\title{
SOLIDARIDAD, SOCIABILIDAD Y COMENSALIDAD EN EL CICLO FESTIVO ASTURIANO (1850-1936)
}

\author{
SOLIDARITY, SOCIABILITY AND COMMENSALITY \\ IN THE ASTURIAN FEAST CYCLE (1850-1936)
}

\author{
Luis Benito García Álvarez \\ Universidad de Oviedo
}

Entregado el 15-10-2012 y aceptado el 3-5-2013.

Resumen: La comensalidad ha desempeñado desde siempre un destacado papel en la búsqueda de la autoafirmación grupal que se produce durante la celebración de fiestas y otros actos de una vida campesina renuente a perder sus elementos más tradicionales. Estas ocasiones favorecen la práctica de la hospitalidad - sobre todo a través del banquete que llega a convertirse en un verdadero estimulador de redes sociales - y conlleva excesos que se oponen a un día a día dedicado al ahorro, afirmando así su voluntad de inversión ritualizada de las pautas sociales normativas. Sea como fuere, el tiempo libre tradicional comienza a modificarse a finales del siglo XIX para dar paso a uno de ocio en su sentido contemporáneo. Significativo es, por ejemplo, que aunque las romerías mantuviesen una ritualización y una apariencia tradicional se organizasen con manifiestos fines mercantiles.

La comunidad tradicional asturiana funcionaba en gran medida vinculada a unos circuitos vecinales de ayuda mutua denominados andechas. En torno a éstas giraba un abundante conjunto de elementos folklóricos, siendo trabajos asociados a ciertas manifestaciones festivas que acabarían por degenerar en una especie de competición entre familias a la hora de organizar el banquete de mayor prestancia, con lo que se perdió su carácter de reciprocidad y su primitiva rentabilidad social y económica. Comer y beber, por último, no dejaría de hacer acto de presencia en las tradiciones que marcaban los ritos de paso vitales.

Palabras clave: Sociabilidad. Comensalidad. Solidaridad. Ocio. Asturias. Restauración. 


\begin{abstract}
Commensality has always played a prominent role in the search for the group affirmation that occurs during the celebration of festivals and other entertainment events of a peasantry against its most traditional. These events promote the practice of hospitality - especially through the banquet becoming anything that comes to a stimulator of social networks -, and excess is opposed to a daily dedicated to saving. In any case, rural celebrations begin to change to make way for contemporary leisure. Significantly, for example, that although the pilgrimages maintained their traditional appearance be organized with a clear commercial purpose.

Traditional Asturian community functioned largely linked to circuitry neighbourhood mutual help: the andechas. Revolved around them a large body of folk elements, and were jobs that were associated with recreational events. This circumstance would eventually degenerate into a competition between families when organizing the banquet, wich will lose its character of reciprocity and social and economic returns. Eat and drink, finally, it would still make an appearance in the traditions that maked rites of passage of life.
\end{abstract}

Key words: Sociability. Commensality. Solidarity. Leisure. Asturias. Restauration. 
La solidaridad constituye un elemento clave para el funcionamiento de la comunidad tradicional que se manifiesta a través de diversas actitudes explicitadas por medio de una simbología ceremonial, y cuyo código determina quién pertenece a ella y quién no. La búsqueda de la autoafirmación grupal, en este sentido, será constante alrededor de la celebración de fiestas y otros actos lúdicos que pueden producirse en familia o a través de los circuitos vecinales de reciprocidad. En el ámbito asturiano la familia - en tanto que unidad social básica con su red de normas y valores - , el parentesco y la vecindad conforman los núcleos primordiales de configuración comunitaria; siendo la aldea y la parroquia, a su vez, los contextos verdaderamente vertebradores de los diferentes grupos presentes en la sociedad tradicional. La estratificación social que resulta de todo ello se articula concediendo un papel preponderante a razones de género y edad y, en menor medida, al estado civil, la profesión o el estatus social. ${ }^{1}$

La proyección de la identidad grupal se manifiesta frecuentemente a través de la comensalidad o de rituales festivos, en los que la reafirmación frente a otros grupos supone un ingrediente esencial. Este fuerte sentido comunitario explica la pujanza, durante mucho tiempo, de un universo ideológico campesino excepcionalmente cerrado a la influencia exterior y resistente a perder sus elementos más tradicionales. De este modo, el mundo agrario constituye una importante reserva de patrones de la cultura popular tradicional y de la compleja sociabilidad del tiempo libre campesino. La fiesta debe ser considerada en este contexto como una manifestación de la existencia social que ocupa una posición central en la estructuración de la vida colectiva. Aparte de sus funciones sociales, constituye un intento de ordenar el mundo y de explicar determinadas realidades mediante el símbolo y el rito, teniendo en cuenta que cada sociedad solamente ritualiza lo que es fundamental para su reproducción social. En la fiesta la comunidad cobra relieve; la gente ocupa los espacios comunes y al amparo de sus símbolos materializa su identidad social. Como contexto complejo, acontecen en ella una serie de rituales y se produce una intensa transmisión de mensajes y un desem-

${ }^{1}$ Edward P. Thompson, «Folklore, antropología e historia social», Historia Social, 3, 1989. Eloy Gómez Pellón, «Sociabilidad e identidad en la comunidad rural», en VVAA, Enciclopedia de la Asturias Popular, vol. III. El ordenamiento social, La Voz de Asturias, Oviedo, 1994. 
peño de roles peculiares que se ejercen como en pocos otros momentos de la vida comunitaria. ${ }^{2}$

De otro lado, la no coincidencia de fiestas en los distintos núcleos cercanos favorece la integración de redes comunitarias locales, la participación masiva y la práctica de la hospitalidad, sobre todo durante la celebración del banquete familiar. Además de todo ello, estas ocasiones llegan a convertirse en un contexto que estimula la fraternidad, que facilita los matrimonios intercomunitarios o que activa enfrentamientos que acaban configurando dos grupos: los locales y los forasteros. La celebración conlleva excesos en la bebida, en la comida o en los vestidos. Es el derroche lo que hace más grande la fiesta, ya que se llevan a cabo actos opuestos a lo cotidiano; son momentos de despilfarro porque se oponen a una vida diaria dedicada al ahorro cuidadoso. En la cultura popular tradicional europea, desde luego, el escenario de mayor relevancia en cuanto a la ingesta de comida y alcohol se refiere era el de la fiesta; ya fuera familiar, comunitaria - como en el caso de las del santo patrón - o de ciclo anual como la Pascua, la Navidad o el Carnaval. En todas estas ocasiones la gente dejaba de trabajar para comer, beber y divertirse.

El tiempo libre tradicional, en cualquier caso, comenzaría a modificarse a finales del siglo XIX para dar paso a uno de ocio en su sentido contemporáneo. Significativo sería, por ejemplo, el hecho de que las romerías, aunque mantuvieran una ritualización y una apariencia tradicional, se organizasen cada vez más en función de un nuevo público urbano e industrial

2 José Luis García, «El tiempo cotidiano en Villanueva de Oscos», en VVAA, Enciclopedia temática de Asturias, t. 9. Folklore, Silverio Cañada, Gijón, 1988. Jorge Uría, «Ocio y tiempo libre en la sociedad rural asturiana. Apuntes para un diálogo entre historiadores y antropólogos», en VVAA, Perspectivas del mundo rural asturiano, Grupo Encuentros en Torazo, Cabranes, 1994; «La cultura popular en la Restauración, el declive de un mundo tradicional y el desarrollo de una sociedad de masas», en Manuel Suárez Cortina (ed.), La cultura española en la Restauración, Universidad Internacional Menéndez Pelayo, Santander, 1999; Joan Prat Canos, «Aspectos sociales y simbólicos de las fiestas», Miguel Roiz, «Fiesta, comunicación y significado».y Salvador Rodríguez Becerra, «Métodos, técnicas, y fuentes para el estudio de

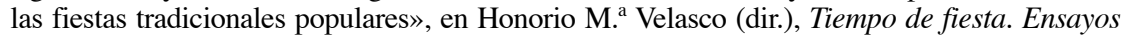
antropológicos sobre la fiesta en España, Tres Catorce Diecisiete, Madrid 1982, pp. 153-168, 7-24 y 30-41; Antonio Ariño Villarroya, La ciudad ritual. La fiesta de las Fallas, Anthropos, Barcelona, 1992, pp. 9-19; Uwe Schultz, La fiesta, Barcelona, Altaya, 1998, pp. 11-15. Sobre la fiesta como proceso comunicativo véase Marianne Mensil, Trois essais sur la Féte, Editions de l'Université de Bruxelles, Bruselas, 1974; Gregory Bateson, Naven, Satanford University Press, Stanford, 1958; Rafael Ruzafa, «Las romerías en Vizcaya en la segunda mitad del siglo XIX. Contrastes y cambio social», en Luis Castells (ed.), El rumor de lo cotidiano. Estudios sobre el País Vasco contemporáneo, Universidad del País Vasco, Bilbao, 1999. 
con nuevos gustos, dándose paso a un tipismo artificial con fines mercantiles. Pese a todo, la fiesta debe ser analizada en la larga duración para comprender los procesos de perduración e innovación, de continuidad y cambio o de funcionalidad distinta de unos mismos ceremoniales.

La serie de transformaciones en la fiesta es amplia: repentinos incrementos demográficos, transformación idealizada de los espacios públicos (la calle, la plaza, la iglesia), cambios en los comportamientos y actitudes habituales, cambios en la dieta y en los modos de ingerir alcohol... Los rasgos arcaicos, a su vez, se modifican, evolucionan, unos son asimilados y otros son transformados. Asimismo, las fiestas captan las mutaciones de valores y las influencias de la cultura dominante, e incorporan aspectos nuevos. En la sociedad moderna, de este modo, han aparecido y se han mezclado con las funciones tradicionales determinadas funciones «societarias», relacionadas más con la comunicación «hacia fuera» - en cuanto a la mercantilización de las costumbres, por ejemplo- que «hacia adentro» - en el sentido de reforzar la identidad social-. En los centros urbanos además, al compás de la industrialización, se produce un aumento del gasto dedicado al ocio entre las clases populares que guarda relación con la progresiva integración de estos sectores en la economía de mercado. ${ }^{3}$

Para el caso asturiano, en suma, se constata que la comensalidad y la sociabilidad asociada al consumo de sidra - que mostraba una refrescante capacidad de adaptación a los nuevos tiempos mientras en otras latitudes triunfaba el consumo de alcoholes industriales - cumplieron una destacada función facilitadora de las relaciones sociales y constituyeron un elemento de relevancia a la hora de fomentar la cohesión grupal. ${ }^{4}$

${ }^{3}$ Peter Burke, La cultura popular en la Europa Moderna, Alianza, Madrid, 1991, Luis Benito García Álvarez, Sidra y manzana en Asturias. Sociabilidad, producción y consumo, Tesis Doctoral, Oviedo, 2008 y Sidra y manzana en Asturias. Sociabilidad, producción y consumo (1875-1936), KRK, Oviedo, 2013; Antonio Ariño Villarroya, La ciudad ritual..., op. cit., p. 10; John Rule, Clase obrera e industrialización. Historia social de la revolución industrial británica, 1750-1850, Crítica, Barcelona, 1990, pp. 302-331. Jorge Uría, Sociedad, ocio y cultura en Asturias (1898-1914), Tesis Doctoral, Oviedo, 1990 , pp. 383 y ss.; «De la fiesta tradicional al tipismo mercantilizado. Asturias a principios del siglo XX», Bulletin d'Histoire Contemporaine de l'Espagne, 30-31, 2000; VVAA, Fiesta, juego y ocio en la Historia, Universidad de Salamanca, Salamanca, 2003.

${ }^{4}$ Luis Benito García Álvarez, Sidra y manzana en Asturias..., 2008; Las representaciones de la sidra. El contexto social de la sidra en la literatura y la pintura asturianas contemporáneas (1850-1936), Museo del Pueblo de Asturias, Gijón, 2008; «Comensalidad, sociabilidad y rituales de consumo. La "espicha" en Asturias en el primer tercio del siglo XX», Historia Social, 71, 2011. 


\section{La romería}

De las múltiples ocasiones festivas que jalonaban el ciclo anual de la actividad campesina sería la romería, sin duda alguna, la más destacada en todos los sentidos; y su formulación tradicional respondía en Asturias a un protocolo con una serie de pasos. El primer día de vísperas había foguera y baile; el segundo, el día grande, amanecía con música de gaita y tambor y cohetes, después venía la misa mayor y la procesión con la subasta del ramo y, tras el banquete familiar, la romería y el baile. Todo este ritual suponía la expresión de un acentuado comunitarismo, y pretendía manifestar la fortaleza del grupo a través de la magnificencia de la celebración. Había, además, otros ingredientes de identificación del grupo comunitario tales como las palizas interparroquiales, que confrontaban nada simbólicamente, y mediante verdaderas batallas a garrotazos, a los grupos de mozos de una u otra comarca.

La romería tradicional seguía siendo, pues, una pieza clave en el tiempo libre de la sociedad asturiana y, como se ha sugerido, el proceso de industrialización la estaba incluso revitalizando, aunque los cambios se hacían cada vez más patentes al compás de la disolución de los marcos sociales tradicionales. Así, a principios del siglo XX los alrededores de las principales zonas urbanas se iban confirmando como una importante zona de ocio, especialmente en los meses cálidos. Por ejemplo, en las inmediaciones de la industriosa ciudad de Gijón, que por otra parte se había convertido en un estimable polo de atracción para el turismo veraniego, concurrían frecuentemente familias de regular posición a organizar sus meriendas campestres; práctica que de las clases medias y de la burguesía ansiosa de tipismo se iría extendiendo a las clases populares urbanas debido a la extensión de la red de tranvías; estableciéndose rápidamente chigres-merenderos en los que, a cambio de la compra de la sidra, las familias obreras podían llevar su propia comida. En este contexto hay que situar el nuevo impulso que adquieren las antiguas romerías; y no sólo las celebradas en parroquias próximas a los núcleos urbanos, ya que el precio cada vez más asequible del billete de tren puso al alcance de estos sectores de público los festejos de comarcas relativamente alejadas, cobrando así una gran vitalidad manifestaciones de un entretenimiento tradicional aparentemente añosas y obsoletas. ${ }^{5}$

\footnotetext{
5 Jorge Uría, Sociedad, ocio..., op. cit., pp. 401-404.
} 
Fue así como el baile y el cante popular, portadores de mensajes y valores del mundo tradicional, fueron sustituidos por nuevas manifestaciones musicales que rápidamente serían tachadas de inmorales por el clero y algunas autoridades; el folklore, que empieza a responder a una lógica diferente, se convierte en una simple atracción turística a través de concursos que lo degradan al rango de curiosidad etnográfica; y la paliza interparroquial, entretanto, acaba convirtiéndose en una pelea callejera donde concurren armas blancas y de fuego, haciéndose necesaria la presencia de la Guardia Civil. También el consumo de sidra comienza a rodearse de un recuperado tipismo y en algunos puestos de bebidas, por ejemplo, se serviría el caldo en las «clásicas pucheras» de barro, en vez de los más modernos vasos de sidra. Por otra parte, a la romería se recurriría también para fomentar la identidad de los nuevos barrios industriales, con lo que aquella se amoldaba de esta forma a las nuevas realidades urbanas. De este modo, iría configurándose un ciclo popular de romerías de barrio que se sumaba al ciclo tradicional, dotándose los vecindarios de una identidad propia con la organización de otro tipo de festejos como los carnavales. ${ }^{6}$

La romería comenzaba, en cualquiera de los casos, con el banquete familiar, al que se invitaba a parientes de otras localidades y en el que la comida era especial para ese día. En la jornada anterior había tenido lugar la foguera, a cuyo calor y lumbre se cantaba y bailaba hasta medianoche y que suponía la víspera de la fiesta grande. El acto de comensalidad desarrollado en torno a él, indispensable en estas ocasiones festivas, se representa como un medio muy efectivo para reforzar los lazos de parentesco, y éste separa a su vez la parte religiosa de la profana - que, por otra parte, cada vez se manifiesta de manera más nítida al irse asimilando romería y verbena - . De otro lado, se debe que tener en cuenta que todas las comidas festivas del año implican un progreso cuantitativo y cualitativo respecto a las ordinarias. La superación de una economía de subsistencia, con la consiguiente mejora de la dieta, rebajaría considerablemente la significación dietética y ritual de estos eventos; pero, en todo caso, en muchos lugares hasta bien entrado el siglo XX constituían una ocasión indispensable para el consumo masivo de carne - aporte fundamental de proteínas suministrado por el ganado de corral, ovino, bovino o, fundamentalmente, porcino-, lubricado por abundante sidra o vino cuando era posible, que se comple-

${ }^{6}$ El Noroeste, 14-VI-1917. Pamela Beth Radcliff, De la movilización a la guerra civil. Historia política y social de Gijón (1900-1937), Debate, Barcelona, 2004, pp. 119-121. 
taba con repostería elaborada por lo general a partir de la leche. En la fiesta cada casería reservaba la parte de mayor enjundia de su producción - la que eliminaba de su alimentación ordinaria - y se comía «lo que nunca se come». Con esta pitanza especial no sólo se fortalecían los lazos sociales, sino que también se alimentaban y suponían un refuerzo de la dieta, aún cuando este se produjese en un instante simbólicamente importante, y no cuando más precisas eran las calorías para el esfuerzo desarrollado en el trabajo. Textos literarios como el relato de Rafael Riera Fray ejemplo o testimonios orales ponen de manifiesto el consumo de «fabes bien untaes» y de la «xarruca» de sidra como prólogo de la romería, continuando el consumo del caldo asturiano durante toda la jornada.

Más o menos coincidiendo con los inicios del periodo considerado se comenzaría a configurar el plato que se podría considerar como la fabada «clásica»; un guiso de alubias blancas con morcilla, chorizo y lacón y/o tocino y azafrán. Baste como muestra señalar que, si bien los asturianos ya consumían fabes con asiduidad - por no decir diariamente-, el texto conocido sobre cocina asturiana más antiguo, La cocina tradicional de Asturias, publicado en la década de 1870 , no hace mención a la fabada. ${ }^{7}$

En cualquier caso entrado el siglo XX, y sobre todo a raíz de la coyuntura derivada de la Primera Guerra Mundial, la alimentación regional experimentaría cambios significativos, especialmente en las comarcas más industrializadas. De este modo, la fabada se convertiría en un manjar al que no se accedía de forma ordinaria, pero que se podía degustar con rela-

7 Una buena descripción del ambiente de esta jornada previa en Armando Palacio Valdés, La aldea perdida, Espasa-Calpe, Madrid, 1986 (1903), pp. 24-32; Luis Benito García Álvarez, Las representaciones...,op. cit.; Ramón Valdés del Toro, «Ecología, trabajo, fiesta y dieta en un concejo del occidente astur», en Carmelo Lisón Tolosana (ed.), Temas de antropología española, Akal, Madrid, 1976, pp. 342-345; Rafael Ruzafa, «Las romerías...», op. cit.; Sobre el banquete véase Mijail Bajtin, La cultura popular en la Edad Media y el Renacimiento, Alianza, Madrid, 1987; Rafael Riera, «Fray ejemplo», en Pomarada asturiana. Escenas y narraciones, Espasa-Calpe, Madrid, 1926, pág 133. Significativo en este sentido es el texto de José Fedz Barcía: «[...]no hay aldeano en todo el Concejo de Gijón que no esté dispuesto a tirar la casa por la ventana, aunque el derroche de ese día le imponga a continuación una dieta cruel y prolongada. Es asombrosa la liberalidad con que en fechas señaladas reciben a sus amistades nuestros labriegos, que, generalmente, se debaten en la estrechez el resto del año», en Sonatina gijonesa, Espasa-Calpe, Madrid, 1929, p. 117; Entrevista a Constantino Díaz Luces (nacido en Caravia en 1910), en Aurelio Francos Lauredo, La memoria compartida. Asturianos en Cuba, Azuzel, Avilés, 1997, pp. 90-91; Eduardo Méndez Riestra, Cocinar en Asturias, Trea, Gijón, 1998, pp. 75 y ss. Untaes: bien provistas de compango. Xarruca: jarra. 
tiva frecuencia en los menús familiares; hecho que no dejaría de explicar la presencia de otros condumios en las mesas festivas. De la abundancia de alubias a la que se ha aludido da cuenta el hecho de que, aunque alcanzasen una buena cotización en los mercados provinciales, fuesen objeto de una lucrativa exportación que llegaba incluso a tierras andaluzas.

Ciertamente la tónica general del periodo muestra un aumento de la variedad y la calidad en la alimentación, y productos que debían de ser importados como los garbanzos, el arroz o la pasta entran a formar parte de la dieta local, al menos en algunos momentos. Por ejemplo, en concejos mineros pero de señalada impronta campesina como Laviana no se entendía, si nos atenemos a lo recogido en la topografía médica del municipio, que una comida festiva no comenzase con un abundante plato de fideos. ${ }^{8}$

Ya a la altura de 1917, la topografía médica del concejo de Gozón indicaba que el menú de fiesta consistía en cocido de garbanzos, carne guisada - pollo en el caso de tratarse de casas pudientes -, arroz con leche, pan blanco, vino, sidra y cocimiento de cascarilla. En el municipio de Aller, por su parte, se contemplaba la ingestión de garbanzos, carne guisada y pitu caleya (pollo de casa), aunque en este caso el postre típico consistía en panchón, dulce elaborado a base de pan de escanda y manteca cuya elaboración requiere un buen número de horas y un costoso trabajo. En el término de Sariego la fabada con abundante compangu compartía protagonismo con el pote de garbanzos; parece ser, eso sí, que fuese cual fuese la pitanza era habitual que el banquete se iniciase con sopa de gallina, constituyendo el postre común el arroz con leche. Por citar un último caso, se pueden encontrar ejemplos en los que el plato principal fuese el arroz con pollo, tal y como ocurría en Ribadesella. ${ }^{9}$

${ }^{8}$ Félix de Aramburu y Zuloaga, Monografía de Asturias, Oviedo, 1899, p. 237; José M. ${ }^{\mathrm{a}}$ Jove y Canella, Topografía médica de Laviana; Madrid, 1927, pp. 100 y ss. y Luis Alonso, Topografía médica del término municipal de Sobrescobio, Madrid, 1932, pp. 55 y ss.

9 Topografía médica del concejo de Gozón, 1917 (sin publicar, sin paginar); Concepción Lada Tuñón y Genaro Alonso Megido, «Delles fiestes nel conceyu d'Ayer», Cultures, n. ${ }^{\circ} 15,2007$, pp. 79, 83 y 87; Joaquín Fernández García, «Les fiestes d'Escoya (Ayer). Estudiu comparativu», Cultures, n. ${ }^{\circ} 15,2007$, p. 114; M. ${ }^{a}$ Antonia Pedregal Montes, «El ciclu festivu en Sariegu», Cultures, n. ${ }^{\circ}$ 15, 2007, pp. 452 y ss; Xandru Martino Ruz, «Les fiestes nel conceyu Ribeseya», Cultures, 15, 2007, p. 500. Aunque el consumo de pan de trigo (importado de América, Rusia o Castilla) de elaboración industrial se había generalizado en los núcleos urbanos e industriales, el uso de la boroña aún se hallaba muy extendido en las zonas rurales; aunque se iría reduciendo progresivamente. Felipe Portolá, Topografía médica de Gijón, Madrid, 1918, pp. 327 y ss.; VVAA, Los asturianos en la cocina. La vida doméstica en Asturias, 1800-1965, Museo del Pueblo de Asturias, Gijón 2005, p. 111. 
Por su valor simbólico y difusión cabe detenerse unas líneas a fin de explicar la significación y particularidades del arroz con leche elaborado en Asturias; plato que, junto a la fabada y la sidra, configura sin duda alguna las señas de identidad gastronómica de la región. No es ninguna novedad señalar que se trata de un postre elaborado en numerosos países $-\mathrm{y}$ en la región construido a partir de un producto alóctono-, pero en este caso ha alcanzado una fama y predicamento inéditos en otras latitudes. Ello se debe seguramente a factores tales como su dilatadísimo proceso de elaboración, que implica un paciente y concienzudo removido del contenido de la olla durante horas y que resulta clave si se pretende obtener un resultado óptimo. Así pues, esta larga cocción, acompañada del azúcar requemado con que se cubre el arroz y que supone la variación más original de la fórmula astur, y la calidad de la leche, son lo que confiere a este contundente dulce su casi unánime positiva valoración. ${ }^{10}$

La peregrinación y la misa también representaban un elemento importante, celebrándose en numerosas ocasiones la romería al pie de los recintos religiosos. Pero de lo que no cabe duda, en cualquiera de los casos, era que la presencia de puestos de sidra y alimentos en estas celebraciones era una constante. Se cuenta con documentación que certifica su presencia ya en el siglo XVI. La sidra llegaba en carros de bueyes, juntándose en ocasiones más de cuarenta. Con el tiempo, se irían instalando en el prado las barracas con mesas y bancos, anejas al carro del país con la pipa cubierta de hojas para que estuviese fresca, y ostentando a la entrada el simbólico y fresco ramo de laurel. También se colocaban entre pación bebidas embotelladas, lo que producía amargas quejas de los puristas cuando la práctica se fue generalizando; solía haber, además, pellejos de vino. Parece ser que la sidra champanizada tendría también un nicho de mercado en estas ocasiones. Por ejemplo, en la romería de Somió de 1911 destacaba una artística tienda de lona en la que se despachaba sidra de la casa Zarracina; la presencia de puestos de comida y bebida también ha sido constatada por grandes escritores asturianistas como Pachín de Melas en una de sus piezas de teatro..$^{11}$

${ }^{10}$ La elaboración del arroz con leche en Eduardo Méndez Riestra, Cocinar..., op. cit., pp. 222 y ss.

11 Esta costumbre de embotellar se pudo generalizar en algunos núcleos urbanos y sus proximidades a principios de la pasada centuria o finales del XIX teniendo en cuenta este testimonio de un anciano gijonés a la altura de 1933: "Aún no había carros de botellas de sidra y sí toneles enramados. [...] Cada pandilla tenía [los] llamados "sacaores" los encar- 
Los taberneros acudían a las romerías e instalaban puestos de sidra y comida. Por ejemplo, el propietario del establecimiento La Higiene de Gijón instalaba en la romería de Granda de 1928 un puesto con sidra del afamado Corsino García de Nava, sirviendo a medio día fabada y por la noche taquinos. Además, fletaba un autobús para clientes y amigos. Parece ser que ya desde finales del siglo XIX los ayuntamientos, al menos los de cierta entidad, trataban de fiscalizar las mercancías que se ofrecían a los romeros. $^{12}$

Otra fuente de gran utilidad a la que se puede recurrir a la hora de tratar de reconstruir las manifestaciones de sociabilidad que acompañan a estas ocasiones se encuentra en los testimonios pictóricos. De este modo, por citar un caso destacado, en algunas obras de Evaristo Valle dedicadas a la temática se pueden observar los puestos de confites, el consumo de sidra embotellada y la afluencia de distintos grupos sociales al festejo. Tal cosa ocurre en su cuadro Romería asturiana, en el que plasma además cierto distanciamiento espacial entre los distintos grupos sociales, identificados con vestimentas diferenciadas; o en su dibujo El indiano y su familia en la romería, en el que se observa el agasajo, en forma de ofrecimiento de sidra, con que el pueblo trata a quien solía ser un habitual sufragador de este acto lúdico. La costumbre de embotellar la sidra y de usar vasos de vidrio para su degustación se irá generalizando, de forma lenta y paulatina según las zonas, desde la instalación en 1843 de una cristalería en Gijón.

Por otra parte, la música tradicional, omnipresente en este tipo de ocasiones, acompañada del tonel de sidra y el consumo en jarras, y del interclasismo de la reunión, es ilustrada por León de la Escosura en Romería asturiana. El gran dominio de la técnica pictórica de este autor - aunque presente la frialdad característica de la pintura costumbrista e histórica de la época- su excelente dibujo y su factura minuciosa, resulta de gran utilidad a la hora de analizar la cultura material representada. Tonel en-

gados de pedir la sidra en el puesto y echarla si era por botellas, o repartirla de la "tariega" (jarra grande) a los vasos», La Prensa, 2-VI-1933. El Correo de Llanes, 25-I-1894. El Noroeste, 29-VI-1911. Pachín de Melás, El filandón, Hércules-Astur, Oviedo, 1992; Luis Benito García Álvarez, Sidra y manzana..., op. cit., passim.

12 El Noroeste, 29-VII-1928. Por cierto que según noticia de 1934 a esta romería habían acudido más de 50.000 personas. El Noroeste, 31-VII-1934. El Litoral de Asturias, 27-IX-1897. Taquinos: pequeños dados de pan ensartados con embutidos u otras viandas y que suelen acompañar al consumo de sidra. 
ramado, gaitero y cortejo es representado por su parte en el cuadro En la barraca de Nicanor Piñole, autor muy inclinado a reflejar las costumbres asturianas y que destaca por su sencillez compositiva.

Así pues, los testimonios proporcionados por las diversas fuentes son pródigos en la representación de las formas de sociabilidad y tiempo libre campesino que sistemáticamente se asocian a la romería. A través de todas estas evidencias se puede reconstruir con bastante detalle, por ejemplo, la importancia en los festejos de las «sabrosas y copiosas comidas, rociadas por la dorada y fresca sidra», así como el clima general de animación a la vista «de robustas rapazas, con el plañir de la gaita y el redoblar del tambor, con los cantos y los bailes y las risas $[\ldots] » .{ }^{13}$ A. Camín relata en sus memorias, refiriéndose a su niñez a finales del siglo XIX y principios del Xx, cómo la sidra seguía siendo el principal consumo alcohólico de la celebración, pero indica a su vez como se le avecinaba, no obstante, la competencia de nuevas bebidas de elaboración industrial, y sobre todo de la cerveza en la época estival. ${ }^{14}$

Por supuesto, y en lo que se refiere estrictamente a la sidra, hay que señalar que en ocasiones la animación de la romería dependía en gran medida de los lagares que estuviesen instalados en la zona, como por ejemplo sucedía en el caso de los festejos de la parroquia ovetense de Pumarín. Incluso podía darse el caso de que alguna fiesta parroquial se celebrase en un lagar, aprovechando el que éste tuviese un espacio adecuado para celebrar el baile, lo que sin duda certificaba la centralidad de la sidra en tanto que ingrediente indispensable en la organización de la fiesta campesina. ${ }^{15}$

El conjunto de estos ingredientes festivos, profusamente documentados en la literatura, se corrobora nuevamente en los testimonios pictóricos. Baile y merienda con sidra, por ejemplo, aparecen representados en una producción pictórica de Mariano Moré, Romería de Granda - que sabe plasmar otros elementos característicos de la reunión, como las ave-

13 Rafael Riera, «Ida y vuelta», en Pomarada asturiana, Espasa-Calpe, Madrid, 1926, pp. 45-46. Una magnífica descripción del ambiente de la romería la ofrece Palacio Valdés en El señorito Octavio, Victoriano Suárez, Madrid, 1921 (1881), pp. 138-156.

14 Alfonso Camín, Mis memorias. Entre manzanos. Niñez por duros caminos, Ayuntamiento de Gijón,Gijón 1978, pp. 191-195. Sobre el desarrollo de las romerías véase también Jesús Pando y Valle, «Las romerías en Asturias», La Ilustración Gallega y Asturiana, 28-VI-1888, p. 225.

15 José M. a López Doriga, «El miércoles de Pumarín», en Siluetas ovetenses, Oviedo, 1899, pp. 169-173. Armando Palacio Valdés, El idilio de un enfermo, FAX, Madrid, 1946 (1883), pp. 210-213. 
llanas y los confites - , en La romería de Ceares o en el titulado simplemente Romería . Como es característico en la trayectoria de este exponente del costumbrismo regional, el eclecticismo, el estilo fácil y claro y el dibujismo están presentes en todas estas producciones; pero, independientemente de todo ello, es evidente que su obra constituye un testimonio de gran relevancia para reconstruir el ambiente y las actividades propias de este tipo de celebración. ${ }^{16}$

Las transformaciones a las que la romería asturiana estaba siendo sometida por el efecto de la industrialización también quedan suficientemente reflejadas en los documentos literarios. La romería, como es sabido, solía ser condenada por las elites sociales al constituir una herencia del irregular tiempo de trabajo campesino. Los patronos se sentían frustrados ante su incapacidad para transformar al obrero mixto en un proletario obediente y disciplinado. Así, los lunes y los días siguientes a los festivos se constataba que hasta un 75 por ciento de las plantillas no acudían a trabajar en algunas etapas del periodo analizado. Una de las preocupaciones principales en este sentido era, otra vez más, el consumo inmoderado de alcohol, condenado por reformadores sociales como García Arenal; quien insistía en que: «Toda la fiesta se limitaba a merendar y a beber sidra y muchos sólo lo segundo». La asociación entre la sidra, la delincuencia o el sexo desordenado y lúbrico planea a lo largo de muchos textos literarios. De estos fenómenos también se hará eco la prensa regional, publicando al día siguiente de las celebraciones las noticias de las consecuencias del consumo inmoderado de sidra que conducen a los dipsómanos al calabozo. ${ }^{17}$

Los intentos de control por parte de las élites sociales de la fiesta venían de lejos. A finales del siglo XVIII, la Junta General del Principado y

16 Otros aspectos como el campo de la iglesia en tanto que lugar de reunión se pueden ver en cuadros como Romería de la Flor de Celso Granda. También destacan pinturas como La danza prima del descriptivo Martínez Abades, El Carmen de Nicolás Soria o El Baile de Santa Marina de Purón Sotres.

17 Citado en Adrian Shubert, Hacia la revolución. Orígenes del movimiento obrero en Asturias, Crítica, Barcelona, 1984, pp. 34-35. De ahí que se pretendiese reducir el número de éstas considerablemente y trasladar las fiestas a los domingos inmediatos, procurando que los días de descanso al año no excediese los 52, más otros trece destinados a las más renombradas fiestas. José Suarez, El problema social minero en Asturias, Oviedo, 1896, pp. 39-40. En todo caso, algunos patronos pretendían acabar por completo con el ocio obrero Datos para el estudio de la Cuestión Social, Silverio Cañada, Gijón, 1980. p. 65; José Fedz. Barcia, Sonatina gijonesa..., opus cit, p. 99; El Noroeste, 30-VI-1897. 
la Iglesia habían interpretado como licenciosos los espectáculos romeros, por lo que la Junta prohibió los bailes mixtos, dictaminando la presencia de jueces que además se encargaban de poner fin al acto media hora antes de que oscureciese. El Obispado, por su parte, proscribía en 1784 el baile entre hombres y mujeres bajo pena de excomunión. Tales medidas obtuvieron un estrepitoso fracaso, lo que da cuenta de la efectividad de las estrategias de resistencia de la cultura popular ante los envites de aquellos que pretendían ejercer un control social excesivamente minucioso. Por otra parte, los testimonios son tajantes a la hora de reflejar el aumento de la violencia que se produce en este tipo de actos y su vinculación directa con el desarrollo de una sociedad mercantilizada y cada vez más inmersa en los circuitos de la industrialización. ${ }^{18}$

No es de extrañar, pues, que la presencia de la pareja de la Guardia Civil se haga indispensable, incorporándose la figura al paisaje habitual de este tipo de celebraciones. La inmoderada ingesta de alcohol, además, podía ser causa también de un relegamiento de parte de las funciones tradicionales del festejo, como expresaba en un artículo para El Noroeste el popular Adeflor refiriéndose al mayor interés que mostraban los mozos en la sidra y las pendencias en detrimento a la atención a las mozas. ${ }^{19}$

La fiesta tradicional también fue objeto de condenas o suspicacias por parte del movimiento obrero, lo que no deja de demostrar su sólido arraigo e incluso su expansión, a la par que visualiza su eventual competencia frente a otras convocatorias de corte político o sindical. Obviamente, al organizar estos actos debían tenerse en cuenta la idoneidad del calendario y, en caso de coincidencia entre mitin y romería, el proletariado no siempre daba muestras de una conciencia política a prueba de las tentaciones que ello suponía. De cualquier modo, los socialistas aprenderían a adoptar rápidamente ante esta circunstancia un modelo de mitin que conjugaba lo festivo y lo político, alcanzando con prontitud un programa lúdico que procuraba hacer el contenido doctrinario más liviano para los participantes; y resultando éste cada vez más parecido a una verdadera ro-

${ }^{18}$ Manuel Gimeno y Azcarate, La criminalidad en Asturias. Estadística (1888-1897), Oviedo, 1900; Armando Palacio Valdés, La aldea..., opus cit., p. 263.

19 Adeflor, «Poesía y salvajismo», El Noroeste, 17-IV-1906. Topografía médica de Tineo (1907), atribuida a Manuel Fernández González, en Francisco Feo Parrondo, Geografías médicas de Tineo de 1886, 1907 y 1913, Principado de Asturias, Oviedo, 1996, p. 134; Antonio Ortega, «Yemas de coco», en Yemas de coco y otros cuentos, Universidad Central de las Villas, La Habana, 1959, pp. 16-17. 
mería (música de gaita y tambor, cohetes, jira campestre); por lo que acarreó inmediatamente las criticas de los sectores anarquistas, celosos guardianes de las esencias revolucionarias. De este nuevo estándar de romería política - no limitada únicamente al ámbito de los socialistas ya que también fueron frecuentes, por ejemplo, entre los republicanos - da cuenta la prensa regional con ocasión de la celebración, por ejemplo, de un Primero de Mayo. ${ }^{20}$

No son las romerías, en cualquier caso, las únicas modalidades festivas catalogables entre estas formas de cultura popular. Otra ocasión lúdica clave en la sociabilidad asturiana la constituye sin duda alguna el carnaval, que en la región recibe el nombre de Antroxu y que, como en la mayor parte de los lugares donde se celebra, supone un abandono radical de las convenciones, de los hábitos y de las costumbres más establecidas, dando paso a la libertad y el desenfreno; y donde la burla y la critica social suponen un elemento distintivo que atrae de inmediato los ataques de los sectores conservadores de la sociedad. Así, en Asturias los mazcaritos se ocupaban en hacer crítica de todo lo conocido, empezando por los defectos de sus vecinos. ${ }^{21}$

La celebración de esta fiesta en los ámbitos urbanos hacía ya tiempo que presentaba una acentuada diferenciación clasista. De un lado el lujo de los salones y casinos, con el galanteo y el baile como elementos distintivos; de otro la calle con su pasión y desenfado y sus criticas graciosas y agudas. Los participantes en el evento preparaban de antemano, a veces ocupando en ello un período de tiempo considerable, distintos números para el carnaval; plasmando en ellos las preocupaciones y la ira soterrada durante el año en forma de caricatura. Había costumbre de cantar ante las casas de los recién casados, de los curas, de los maestros o de cualquier tipo de autoridad. No deja de ser significativo que en muchas Ordenanzas municipales de la época las manifestaciones del carnaval estuviesen fuertemente legisladas, contemplando incluso acciones punitivas, cuando los blancos de las puyas eran alcaldes y concejales. También la prensa socialista y anarquista acabaría condenando estas manifestaciones desordenadas de carácter eminentemente popular, pero en las que descubrían ocasiones para los excesos alcohólicos y el desorden; que condenaban en la

${ }^{20}$ Citado por J. Uría en Sociedad..., op. cit., pp. 409-412; El Avance, 13-V-1900; El Noroeste, 23-VI-1903

${ }^{21}$ Sobre el carnaval véase Julio Caro Baroja, El carnaval, Alianza, Madrid 2006. Joan Prats y Jesús Contreras, Les festes populars, Barcelona, 1982. 
taberna o en la romería. Su condena era en este sentido muy nítida. De todas maneras la diversión continuó siendo el rasgo definitorio del periodo, como queda puesto de manifiesto en la prensa de la época; y la comida y la bebida sus compañeras inseparables. ${ }^{22}$

En los ámbitos rurales la fiesta siguió conservando sus elementos tradicionales, y de hecho fue muy frecuente hasta el primer cuarto del siglo XX. Los jóvenes se disfrazaban y enmascaraban, en ocasiones con los mismos atuendos que habían utilizado durante unas celebraciones navideñas de las que el carnaval reproducía parte de sus protocolos; de hecho en estas fechas también solía pedirse el aguinaldo. Tampoco faltaban, bien asociados a los guirrios y zamarrones (mascaradas de invierno típicas en Asturias) o bien independientemente, grupos disfrazados que representaban farsas y comedietas. Se trata de las madames, los galanes, los vieyos, el ciego, el lazarillo, el diablo, el oso, el húngaro y una larga lista de personajes bien perfilados. En sus parodias se caricaturiza la sociedad aldeana a través de la ridiculización de los acontecimientos cotidianos. Por otra parte, desde finales del siglo XIX, aparecerán nuevos tipos satíricos como el médico y el boticario; que hablaban en castellano - frente al bable empleado por los demás personajes-, evidenciando así un choque cultural manifiesto entre el viejo fondo tradicional y las novedades recientes. Era común también en estos días que los mozos hiciesen trastadas, tales como arrojar piedras en las tierras de labor, arrancar portillas, esconder los carros o aquello que debido a su «ingenio»o al grado de euforia etílica les sugiriese. Una costumbre muy extendida era la de correr el gallo, consistente en la caza y decapitación de uno de estos animales de corral. ${ }^{23}$

El carnaval en Asturias solía abrirse el Jueves de Comadres, de claras connotaciones matriarcales, celebración muy extendida por toda Europa pero que en algunas zonas de la región adquiría un significado especial al ser un reconocimiento a la figura de la madrina, que ese día invitaba a sus ahijados a una jira campestre en la que merendaban bollos preñaos, naranjas y sidra y que tenía gran arraigo en Pola de Siero, Gijón y Villaviciosa. Tras este anuncio, los tres días tradicionales de la fiesta eran el Domingo

22 «El carnaval», en La Aurora Social, n. ${ }^{\circ}$ 122, Oviedo, 1902; «Tribuna libre. A propósito del carnaval», El Libertario; Constantino Cabal, Contribución al diccionario folklórico de Asturias, vol. IV, IDEA, Oviedo, 1953, pp 110-112 y 150-189; Protasio González Solís, Memorias asturianas, Madrid, 1890, pp. 515-516; El Correo de Llanes, 5-II-1894.

${ }^{23}$ Eloy Gómez Pellón, Las mascaradas de invierno en Asturias, RIDEA, Oviedo, 1993, pp. 69-72; Elviro Martínez, Tradiciones asturianas, Everest, León, 1982, pp. 53 y 74. 
Gordo, el Lunes de Quincuagésima y el Martes de carnaval. Este último día, o el Miércoles de Ceniza, tenía lugar desde el siglo XIX el Entierro de la sardina; acto burlesco de apariencia litúrgica que simboliza la muerte de don Carnal y el nacimiento de doña Cuaresma, y en el que la ingesta de bebidas acostumbraba a ser masiva. ${ }^{24}$

Además se hacían excesos en la comida y en la bebida, alcanzando la comensalidad en este caso un nivel no superado en ninguna otra fiesta tradicional. Obviamente la trasgresión característica de estos días alcanzaba a todos los órdenes de la vida, y especialmente a la alimentación. La celebración del Antroxu suponía, pues, una ingesta desmedida de comida y bebida. Algunos autores sostienen - aunque sea esta una cuestión debatida - la asociación que en ciertas economías campesinas pudiera establecerse entre la fiesta - con el reforzamiento de la dieta - y las épocas de mayor trabajo y gasto energético; además de con las épocas más adversas del ciclo climático - y la consiguiente ausencia de alimentos dada la dificultad de almacenamiento-. Esta última situación iba indefectiblemente unida también, como es obvio, al carnaval tradicional. Ello contribuiría a explicar que la matanza del cerdo se realizase en estas fechas que suponían una despedida de la carne por la cuaresma, constituyendo su consumo masivo uno de sus mayores atractivos; a ello se sumaban los dulces tradicionales como casadielles, frisuelos (fayuelos, fayueles, fiyoles), buñuelos y otros alimentos de alto contenido calórico además de, lógicamente, la bebida. ${ }^{25}$

${ }^{24}$ Constantino Cabal, Contribución..., op. cit., p. 128. Elviro Martínez, Tradiciones..., op. cit., pp. 39-66.

25 Eloy Gómez Pellón, Las mascaradas..., op. cit., pp. 76-77. Elviro Martínez, Tradiciones asturianas..., op. cit., pp. 47-53. Ramón Valdés del Toro, «Ecología, trabajo y fiesta...», op. cit., Luis Benito García Álavarez, Sidra y manzana..., op. cit., pp. 192 y ss. La carne fue vista siempre como un síntoma de prosperidad. Si bien se puede constatar el consumo de vaca o cordero, el cerdo constituyó la principal fuente de proteínas en una dieta en la que éstas acostumbraban a escasear. Su carne fresca, el adobu, constituían en los días de matanza un rito de solidaridad repetido en cada casería, al igual que sucedía en el resto del país; pero era en los embutidos donde mejor se manifestaba su presencia, dosificada a lo largo del año con mayor cicatería de la deseada la mayor parte de las veces. De este modo, la morcilla ahumada con leña de roble, los chorizos, los choscos y butiellos, los xüanes, moscancias, bollas, fariñones y emberzaos, forman parte del amplio abanico de embutidos asturianos. Las casadielles son una especie de empanadillas, fritas u horneadas, rellenas de un engrudo elaborado a base de nuez o avellana; quizá se puedan relacionar con las quesadillas que Caro Baroja señala como plato típico del carnaval. Eduardo Méndez Riestra, Cocinar..., op. cit., pp. 181 y 233. 
Así, la cena del primer día de matanza debía consistir por lo general en sopa de hígado, pollo con patatas, arroz con leche o brazo de gitano y sidra. En concejos como Cabranes y Sariego se preparaba un pote con abundante cantidad de carne porcina y el xuan, que era una gran morcilla embutida en el estómago del cerdo que se rellenaba con algunas otras partes del animal; toda esta comida se regaba con abundante sidra y se concluía con fayuelos, picatostes (torrijas) y otras frituras. También era costumbre en aquellos lugares regalar a los pobres del pueblo una cesta con chorizos, morcillas, tocino, huevos, alubias, patatas, harina, fruta y sidra. La matanza, por otra parte, es una de las muchas formas que reviste la ayuda solidaria y la buena vecindad, ya que supone una reciprocidad equilibrada que se refuerza además con el convite; lo que asienta este tipo de redes sociales reforzadas con estímulos positivos y reciprocidad. ${ }^{26}$

\section{Los circuitos de ayuda mutua}

Como se ha apuntado, la comunidad funcionaba como tal gracias en gran medida a unos circuitos vecinales de ayuda mutua. Este hecho se plasma claramente en la realización de una serie de trabajos periódicos en grupo denominados en la región andechas. La ventaja del establecimiento de estas relaciones de reciprocidad respecto al trabajo es que, de este modo, pueden llevarse a cabo labores que de otra forma desbordarían la capacidad de la familia campesina, que queda dotada así de una razonable seguridad a la hora de planificar sus actividades. En su ya clásico trabajo sobre el occidente asturiano, Ramón Valdés del Toro establecía la diferencia entre «ayuda» como circuito de solidaridad y «socorro» como cooperación para subsanar alguna contingencia desfavorable - como por ejemplo la pérdida de una res o daños en alguna construcción -, en las que la presión y la consideración vecinal variaban en la exigencia de solidaridad. ${ }^{27}$

26 Sobre la matanza como acto de comensalidad y sociabilidad véanse los trabajos del monográfico dedicado a tal asunto en Cultures, 9, 1999; véase además José Antonio Fidalgo, El gran libro de la cocina asturiana, Gran Enciclopedia Asturiana, Gijón, 1996, p. 388; Emiliano Pérez Junco, Cabranes. Notas sobres su historia, vida y arte en el concejo, Autor, Gijón, 1990, p. 283.

27 Juan Oliver Sánchez, «Antropología cultural», en VVAA, Enciclopedia temática de Asturias, t. 8. Etnografía, Silverio Cañada, Gijón, 1988. Ramón Valdés del Toro, «Ecología...», op. cit., pp. 278-332. 
Generalmente, se recurre a la andecha a la hora de afrontar trabajos que no pueden esperar, tales como la siega, o que necesitan de abundante mano de obra, como el deshojado y enristre del maíz (esfoyaza), tareas en ayuda de ausentes o de viudas, etc. La realización de obras del común del pueblo, en cambio, recibe el nombre de sextaferia, y consiste generalmente en la composición y arreglo de los caminos, o la reparación de templos, escaleras, canalizaciones de agua u otras obras. En la sextaferia lo propio es que participe un individuo de cada grupo doméstico o, al menos, realice una aportación económica fijada en virtud de alguna asamblea o reunión comunitaria en su forma más canónica - concejo abiertocuyo acuerdo es vinculante. El hábito consagraba la socialización de los problemas a través de la discusión comunitaria y la posterior adopción de decisiones acatadas por todos, so riesgo de soportar un aislamiento difícilmente sobrellevable en una pequeña comunidad.

La andecha, en todo caso, no exige el pago inmediato de la ayuda que, aunque teóricamente es voluntaria, constituye como acaba de decirse una obligación de facto que, caso de no cumplirse, marginaba a la unidad familiar; excepción hecha de familias pobres o con un enfermo que podían recibir ayuda sin aportar nada a cambio. También los vecinos con necesidad de construir o arreglar una cuadra o casa derruida, o ante la muerte del ganado, o la perdida de la cosecha, recibían ayuda en forma de fuerza de trabajo o de bienes en especie o metálico; a no ser, eso sí, que la desgracia se produjese por negligencia del campesino o que fuese el daño de tal magnitud que ni siquiera con la ayuda comunitaria pudiese recuperarse la familia. La ayuda recibida, en todo caso, no exigía compensación.

La integración de una casería en uno de estos circuitos de reciprocidad es la norma que impone la convivencia en el agro asturiano, hasta el extremo de que evitarlos supone el aislamiento si no existen razones sólidamente fundadas para ello. Por otra parte, también la casería cuenta con una red de parentesco lo suficientemente amplia para generar otros circuitos de reciprocidad que comúnmente son suficientes para hacer frente a las necesidades más perentorias. ${ }^{28}$

28 Sobre la andecha véase, por ejemplo, Jesús García Fedz., Sociedad y organización tradicional del espacio en Asturias, IDEA, Oviedo, 1976; Francisco Tuero Bertrand, Instituciones tradicionales asturianas, Ayalga, Salinas, 1976; César Álvarez-Linera Uría, «Derecho tradicional asturiano», en VVAA, Enciclopedia temática de Asturias, t. 9, Silverio Cañada, Gijón, 1988. 
Alrededor de la andecha, por otra parte, giraba un abundante conjunto de elementos folklóricos, asociándose los trabajos a ciertas manifestaciones lúdicas y festivas. Por ejemplo, la casa que recibía la ayuda daba ese día una cena que recibía también el nombre de andecha, soliendo acabar ésta en una reunión donde el canto y el baile estaban presentes. El desarrollo económico asociado a la orientación ganadera del campesinado regional y la tecnificación del campo, de todos modos, trajo como resultado precisamente el acentuar cada vez más sus vertientes lúdicas, y estaría en el origen de la decadencia de esta institución tradicional; ya que se acabaría por degenerar en una especie de competición entre familias a la hora de organizar el banquete, con lo que perdió su carácter de reciprocidad, su justificación tradicional, y su rentabilidad económica. De la planificación y desarrollo de estas actividades se ha ocupado el folklorista C. Cabal, así como de la sociabilidad y comensalidad que las rodea, señalando cómo durante el trabajo se daba de comer, merendar y cenar a los participantes. Los alimentos presentes podían ser, tal como señala el etnógrafo, patatas con carne y tortilla a la comida, y queso y jamón a la merienda; así como «una atrocidad de sidra» o unas botellas de vino. ${ }^{29}$

También se perdería el carácter de trabajo de invierno, y a techo - en la medida que estas labores estaban perdiendo su lógica al compás de la inserción del campesinado en la economía de mercado-, que era propio de esfoyazas y filandones - aunque en cierto modo continuasen aunando su doble función de quehacer agrario y diversión campesina en un periodo del año escueto en cuanto a romerías, y a las que servían de sustitutivo - en favor de una vertiente cada vez más festiva que, sin embargo, contribuía a reforzar el sentimiento comunitario al igual que celebraciones como los amagüestos y fornaos de castañas, y que seguían siendo ocasiones muy propicias para el cortejo. Se ofrecía también una merienda a quienes ayudaban a «andar a la yerba», pudiendo acabar la tarea en ocasión igualmente festiva tal y como se descubre, por ejemplo, en la novela de García Miñor Caras negras. ${ }^{30}$

29 Constantino Cabal, Las tradiciones populares asturianas II. La familia, la vivienda y oficios primitivos, GEA, Oviedo, 1992, pp. 16-17. Para inaugurar la casa se celebraba el ramu, donde el consumo de sidra y alimentos también se hallaba bien presente. De la vertiente cada vez más lúdica de estas reuniones da cuenta la cada vez mayor intransigencia de las autoridades, tanto de la Junta General del Principado como del obispo de Oviedo ya desde finales del siglo XVIII.

30 Sobre el trabajo de la hierba véase VVAAA, La cultura de la yerba n'Asturies, Cultures, 7, 1997. Antonio García Miñor, Caras negras, Aguilar, Madrid, 1955, p. 64. 
Se hacía por andecha, a su vez, la labor de tierrar, que consistía en subir tierra de la parte más baja de la finca a la más alta a fin de contrarrestar el desplazamiento natural que ocasionaban las faenas cotidianas. La tarea culminaba con una merienda en la que solían comerse castañas, queso con borona, manzanas y sidra, yendo mejorando con el tiempo los manjares de un festín que contemplaba la presencia de tortilla y chorizos. ${ }^{31}$

Por su parte, la esfoyaza, esbilla (nombre este que también se aplicaba a las operaciones de extracción de su vaina requeridas por los guisantes y habas) o esfueya que consiste en desojar y enristrar las mazorcas de maíz como se ha dicho, constituía una ocasión propicia para conjugar el trabajo a techo y el ocio campesino. Para el desarrollo de esta tarea, las panoyes se solían almacenar en el estragal o portal de la casa, y alrededor se situaban los esbilladores que iban echando las ya abiertas en los goxos (cestos) o directamente en un montón donde luego se situaban los enristradores, eligiendo cada uno de ellos a una moza para que les alcanzase el fruto. Para evitar que las ristras se rompieran solían incluirse en el tejido, mimbres, juncos, espadañas o fibras similares. Cuando una ristra se rompía, se denominaba al hecho parir la ristra, quedando en mal concepto quien la había hecho; de ahí que se generase cierta competencia por hacer las mejores. Las panojas que quedaban sin hojas se apilaban separadas y luego se clasificaban; las mejores se subían al desván para secarlas y luego se aprovechaban lo mismo que las enristradas, que se colgaban en el hórreo o en el corredor de la casa; las defectuosas se usaban como pienso para el ganado. Con el tiempo las funciones festivas fueron primando sobre las de reunión de ayuda vecinal y no sólo tenían lugar en invierno. Así, al menos tras la Primera Guerra Mundial, la costumbre subsistía como reunión comunitaria, no necesaria ciertamente desde el punto de vista de la racionalidad productiva, pero sí muy conveniente desde el del tiempo libre de trabajo. Lo mismo ocurría con las menos frecuentes esbillas de alubias o guisantes. A la altura de 1923 J. de Villalaín, en su topografía médica del concejo de Illas, constataba entretanto la existencia de algunos otros viejos usos como esfoyetas o filetas. Del desarrollo de la esfoyaza han dejado excelentes testimonios autores como Jovellanos, o Alfonso Camín; el primero, con su habitual rigor y concisión en las descripciones, describiendo el desarrollo de la reunión tal y como podía ser a lo largo del siglo XVIII: la merienda que se ofrecía a los concurrentes a base de tortilla de sardinas, jamón, boroña,

31 Emiliano Pérez Junco, Cabranes..., op. cit., p. 262. 
queso, manzanas o peras cocidas, en unos lugares; un panecillo como de media libra, en otras; o, en ciertos sitios la garulla, consistente en corbates (castañas asadas) y peras y manzanas crudas. El segundo, dando cuenta de la evolución de la celebración a lo largo de más de un siglo, añade de todos modos precisiones sobre los turnos de celebración entre las distintas casas de la aldea, a la vez que informa de las complejas formas comunitarias de la reunión; asociada ésta con toda seguridad a los relatos de la tradición oral. De otro lado, la convocatoria es un acto propicio para el cortejo, uno de sus núcleos funcionales sin duda. El contenido lúdico de la reunión se ve acentuado por los juegos que se desarrollan durante la velada; entre estos destacan «el rey» $\mathrm{y}$ «el zurrón» $\mathrm{O}$ «la alpargata». ${ }^{32}$

La esfoyaza, en fin, también aparece asociada, como no podía ser menos, a comidas comunitarias y a libaciones colectivas donde la sidra ocupa un destacado papel. Como se ha señalado se obsequiaba a los asistentes con manzanas crudas o asadas, nueces, castañas, sidra y licores; presentes que recibían el nombre de garulla. Muchas veces se daba sidra del duernu del lagar de la propia casa o también sidra del año anterior, en ocasiones los tradicionales frisuelos, o tortilla de sardinas y tocino. ${ }^{33}$ En la última casa en la que se llevaba a cabo esta ayuda de buena vecindad, tenía lugar, como ya se ha visto, la celebración del ramu, que suponía un convite de mayor envergadura y por el que se reforzaba el marcado carácter comunitario del acto a través de la comensalidad. Como no podía ser menos, la música tradicional acompañaba la celebración de éste acto lúdico. ${ }^{34}$

32 Sobre la esfoyaza, Luis Benito García Álavarez, Sidra y manzana..., op. cit., y Las representaciones de la sidra..., op. cit.; José de Villalaín, Topografía médica del concejo de Illas, Imprenta de la Ciudad Lineal, Madrid, 1923, p. 47; Jovellanos, Diarios. Tomo I, Oviedo, 1953, pp. 142-143. Emiliano Pérez Junco, Cabranes..., op. cit., p. 258; véase también Florencio Friera, Patrimonio histórico y cultural del concejo de Sariego (Asturias), RIDEA, Oviedo, 2001, pp. 583-584.

33 Octavio Bellmunt y Fermín Canella, «De Vita et Móribus...», Asturias I, Gijón, 1895, pp. 26-27. Alfonso Camín, Mis memorias..., opus cit., pp. 266-268. Por su parte, Aurelio de Llano, que con su aguda capacidad de observación ha sido uno de los folcloristas asturianos que mejor ha sabido captar los matices de las tradiciones regionales, nos ofrece una completa descripción de la costumbre tal y como la recogió en sus estudios de los años veinte. La descripción del etnógrafo recoge punto por punto los detalles de su organización que se ha visto hasta ahora, aunque añadiéndoles enriquecedoras precisiones acerca de la planificación del trabajo del enristrado, o sobre los juegos y retozos de mozas y mozos. Del folklore asturiano. Mitos supersticiones, costumbres, IDEA, Oviedo, 1983 (4.a), pp. 223-224.

${ }^{34}$ Rafael Riera, «Una esfoyaza», en Pomarada..., opus cit., pp. 189-201. El cuento había sido publicado por El Noroeste el 20 de noviembre de 1911. 
En invierno, las mujeres solían reunirse en torno al fuego para hacer fila, (filandón, polavila o también calietsa cuando es de lino) a la luz de la lumbre o de algunos candiles, contribuyendo las participantes a pagar el aceite o saín consumido en el alumbrado de los candiles. En este acto, al que se ponía fin cuando llegaban los meses de primavera, estaban presentes relatos de la tradición oral, cuentos, cosadielles (adivinanzas), coplas y leyendas, que servían de excelente vehículo de transmisión cultural; era también una ocasión sumamente propicia para el cortejo. La reunión comenzaba tras la cena; las mozas solteras y sus madres, y también las casadas, cogían la rueca y se dirigían hacia la casa donde se celebraba la fila; siendo costumbre filar un día para la dueña de la casa donde se llevaba a cabo, o hacerle una pequeña contribución en metálico. Más tarde llegaban los mozos y comenzaba una auténtica fiesta popular a la que también solían acudir niños. Los juegos y bromas características de este acto lúdico se parecerían bastante a los de otras reuniones festivas de parecido corte. Se solía jugar, por ejemplo, al igual que en la esfoyaza, al zapato o al zurrón. ${ }^{35}$

El consumo de sidra también estuvo muy presente en estos trabajos de invierno y a techo, sobre todo dada su vertiente cada vez más lúdica y que, como había sucedido ya con costumbres tales como la de la andecha, acabaron acarreando su disolución. Las autoridades eclesiásticas, desde luego, habían condenado su inmoralidad. Los mozos no hilaban, pero sí que podían rastrillar o devanar y, más frecuentemente, repartir las castañas y la sidra. Como las mozas tenían las manos ocupadas, los mozos las pelaban y se las daban a la boca. En algunas zonas se celebraban los jueves y los sábados, en otras miércoles, sábados y domingos y en algunas a diario y, ya a principios del siglo XX, parece ser más un baile de jóvenes - mientras las personas de más edad hilan - que una reunión de trabajo. En ocasiones se hacía un amagüestu (asado de castañas) durante la fila, pagando las mozas las castañas y los mozos la sidra. ${ }^{36}$

35 Gonzalo Morís Menéndez, «La lana y el lino», en Enciclopedia de la Asturias Popular. I. El hombre y el medio, La Voz de Asturias, Oviedo, 1994, pp. 145-160; M. Díaz González, «El filandón», Cubera, 14, 1989; Octavio Bellmunt y Fermín Canella, «De Vita et Móribus...», op. cit., p. 26.

36 Vicente Velarde, «Usos y costumbres de los pueblos limítrofes a la villa de Salas», en Anales de la Universidad de Oviedo 1901, Establecimiento Tipográfico de Adolfo Brid, Oviedo, 1902, p. 109; Celestino Valledor, «Usos y costumbres en el concejo de Allande», en Anales de la Universidad de Oviedo 1903-1905, Establecimiento Tipográfico de Adolfo Brid, Oviedo, 1905, pp. 33-39. Elviro Martínez, Tradiciones asturianas..., op. cit., p. 66. 
Sea como fuere, parece ser que lo sustantivo de estas reuniones en las que se relataban cuentos, se recitaban romances y coplas o se hacía una lectura comunitaria del periódico o del folletín, y donde se cortejaba o rumoreaban las noticias, era el desarrollo de la sociabilidad campesina. En realidad, de la fila o de la esfoyaza sólo quedaba muchas veces, y ya en los años de la Gran Guerra, el simple nombre que se daba a una reunión semanal que en otro tiempo había tenido componentes laborales.

Otras ocasiones de carácter festivo y básicamente ligadas al cortejo son los fornaos y magüestos de castañas, donde el consumo de sidra - que en estas reuniones de invierno podía ser dulce o poco fermentadase encuentra muy presente. Hay que señalar que, hasta la llegada del maíz y las patatas, las castañas constituían uno de los principales alimentos de la monótona dieta del campesinado asturiano y que su consumo seguiría estando muy presente durante toda la época contemporánea. Los fornaos se celebraban en las casas, y recibían tal nombre porque las castañas se asaban en hornos. Los testimonios recogidos por folkloristas como Aurelio de Llano son, una vez más, sumamente ilustrativos en este sentido. El magüestu (amagüestu o magosto) puede ser una reunión de mozas y mozos amenizados por la música y el baile, o una celebración casera organizada por una familia. Era costumbre que las mozas se encargasen de aguetar (recoger) las castañas y los mozos corriesen con los gastos de la sidra. En todo caso, y como lo describe con su habitual concisión de Llano, las vertientes festivas parecen dominar claramente en su estructura. ${ }^{37}$

Volviendo de nuevo a los cortejos a que servía de cobijo el amagüestu, la vigilancia con que eran observados por las autoridades no era ni mucho menos nueva. El obispo Pisador los había acusado ya, en la segunda mitad del siglo XVIII, de ser una mala y perniciosa costumbre por los peligros que corrían mozos y mozas en tales sesiones nocturnas, y daba aviso a los curas de que debían proscribirlas. Las actitudes de censura hacia las fiestas campesinas tenían, por tanto, una larga historia y una trayectoria que ilustraba tanto el pertinaz empeño de la iglesia por fiscalizar las costumbres, cuanto la insistencia de los sectores populares en continuar con un ejercicio una y otra vez condenado a lo largo de los años. ${ }^{38}$

En todo caso, este tipo de celebración donde lo sustantivo, al margen del cortejo, lo constituye el consumo de castañas y sidra, se puede ex-

\footnotetext{
37 Aurelio de Llano y Roza de Ampudia, Del folklore..., opus cit., pp. 220-221.

38 Octavio Bellmunt y Fermín Canella, «De Vita et Móribus...», op. cit., p. 27.
} 
tender a otro tipo de reuniones con distintos núcleos funcionales y fuera de los ámbitos campesinos. El amagüestu, de hecho, podía convertirse en una simple fiesta corporativa de un gremio u oficio, tal como ocurría, por citar un caso, con los pescadores del oriente asturiano residentes en la ciudad de Gijón. ${ }^{39}$ La sidra y las castañas, por lo demás, podían también arropar muy distintos actos del propagandismo católico, aunando al cante y el baile, y al distendido tipismo que representaban los «diálogos en bable», el indudable atractivo culinario. ${ }^{40}$

\section{Los ritos de paso}

En los complejos procesos de socialización campesina, por otra parte, operaban instancias particularmente activas como la formada por los mozos, que daban vida a tradiciones rituales de muy diverso tipo como los aguinaldos, devotos, carnavales, etc., y en donde, como bien es fácil suponerse, hacían como de costumbre acto de presencia los alimentos. La mocedad era un grupo organizado - definido por sexo y estado civily sumamente activo que operaba a partir de solidaridades temporales y obligatorias. Su labor en los actos simbólicos de autoafirmación de la comunidad le confería una especial significación. En el caso masculino, esta institución engloba a los mozos solteros de entre quince y treinta años (o más). Su funcionamiento está reglado por la costumbre, siendo las normas especialmente rígidas para quienes acaban de ingresar en el grupo. Obviamente, lo que se realiza en el seno de la mocedad es el tránsito a la vida adulta de acuerdo con los valores comunitarios. La mocedad femenina, entretanto, constituía un grupo mucho menos institucionalizado debido al abrumador dominio que sobre los espacios de sociabilidad públicos tenían los hombres en la sociedad rural. ${ }^{41}$

Y la inclusión en este grupo se realiza a través de un rito de paso consistente precisamente en el pago de bebida para todos los demás. Ello daba paso a varios años de subordinación a los mozos mayores, que eran quienes tomaban las decisiones sobre las actuaciones a llevar a cabo. La salida del grupo se producía con otro rito de paso: el matrimonio, que suponía la creación de una nueva unidad de producción y consumo. Así, en

\footnotetext{
39 El Noroeste, 12-XII-1904.

40 El Correo de Llanes, 20-XI-1893.

41 Eloy Gómez Pellón, «Sociabilidad e identidad...», opus cit.
} 
este sector de la sociedad se observaban unas relaciones de poder a través de las cuales los recién llegados obedecían a los mayores a cambio de su aceptación como miembros de la institución, obteniendo además protección y participando de nuevas formas de sociabilidad.

El papel de los mozos era sumamente activo en los actos lúdicos de la vida aldeana, lo que les dotaba de una especial significación en la consecución de la solidaridad y cohesión comunitaria. Además, la pertenencia a la institución conllevaba también una serie de deberes, como por ejemplo el traslado del ganado a los pastos de verano, la localización de las reses extraviadas y la devolución a sus dueños, la ayuda a los vecinos con apuros, etc. El escenario predilecto de la actuación de estas cuadrillas de mozos lo constituía un calendario festivo que, en el caso asturiano, se presentaba muy elaborado y que provenía, en gran medida, de la cristianización de ciclos rituales antiguos emprendida por la Iglesia, amalgamando tanto celebraciones propias de los pueblos europeos agrarios, como celebraciones del ciclo festivo romano. El ciclo navideño en la región, por ejemplo, comenzaba por Santa Lucía, siendo los días de Navidad, san Silvestre y Reyes las ocasiones preferidas por la mocedad en este caso para llevar a cabo las mascaradas invernales y los aguinaldos. Estas fiestas están caracterizadas por los disfraces y las acciones burlescas. Dentro de cada cuadrilla existía una jerarquía con cometidos muy precisos. El caporal o mayoral, generalmente el soltero más viejo, dirigía la ronda; el bolsero, llevaba la contabilidad; y podía haber dos contadores y un rezador. Las mozas, por su parte, también podían pedir el aguinaldo. ${ }^{42}$

En similares términos había recogido esta tradición A. de Llano en los comienzos del pasado siglo, quien señala que el aguinaldo se pedía en unos lugares el día de Reyes y en otros la víspera del año nuevo, acto que se acompañaba de canciones con letras variadas según las comarcas. Según su testimonio una vez concluida la ronda, sobre las diez de la noche los mozos se reunían en casa de un vecino, cocían las castañas en el horno y obsequiaban con ellas y con sidra a las mozas allí reunidas. En fin de año tenía lugar la celebración de los devotos (también llamados los estrechos), que consistía en la formación de parejas por sorteo y que debían ac-

42 Eloy Gómez Pellón y Gema Coma Gónzalez, Fiestas asturianas, Caja de Ahorros de Asturias, Oviedo, 1985; Elviro Martínez, Tradiciones asturianas..., op. cit., p. 12; Constantino Cabal, Las tradiciones populares asturianas I. individuo y sociedad en la Asturias tradicional, GEA, Oviedo, 1992, pp. 77-81 y 107; Luis Benito García Álvarez, Sidra y manzana..., op. cit., passim. 
tuar como tales mientras durase la fiesta. Previamente se determinaba qué edades debían tener los jóvenes que participasen y qué actividades debían realizar, lo que estaba regulado por la costumbre. En este tipo de sociedades cerradas, los devotos eran una forma de regular las relaciones previas al noviazgo, intentando asegurar lo máximo posible la endogamia en la misma unidad de población. Así lo recogen las prospecciones folcloristas realizadas en la época: El día de reyes, el devoto va a buscar a su casa a la devota que le tocó en suerte, la lleva al baile que se celebra en el sitio de costumbre, y la obsequia con dulces, vino o sidra». ${ }^{43}$

Los ritos de paso son fenómenos de gran trascendencia para el funcionamiento y la perpetuación de la comunidad. Son comunes a todos los grupos humanos, alcanzando su más completa expresión en sociedades de carácter estable y a pequeña escala. Buscan, en definitiva, un equilibrio entre el cambio y la continuidad. Por ejemplo, en la sociedad tradicional asturiana solía ofrecerse un banquete para celebrar una boda. Éste tenía una gran importancia no sólo como celebración que sanciona la aceptación de los nuevos esposos como nueva unidad de producción y consumo, sino también como encuentro entre los dos grupos de parentesco que firmaban una alianza de vida y de patrimonio. Con frecuencia se cocinaba en casa lo que se iba a comer en la celebración y después se llevaban al chigre o merendero las ollas, para allí consumir nada más que las bebidas. Si sobraba comida, se hacía un paréntesis en el baile de la tarde y lo terminaban. Por ejemplo, en el concejo de Cabrales era costumbre que el novio pagase a sus expensas una fiesta a sus convecinos y, de no cumplirse este precepto, la vida en el pueblo podía, al menos por algún tiempo, tornarse incómoda. Existía también la tradición de las tornabodas, que en algunos lugares se celebraba una semana después del evento y en otras el primer festivo tras el enlace. Está ocasión consistía en una comida, pero con menor número de invitados. Los regalos de boda solían ser productos de la tierra, llegando en ocasiones a reunir una modesta cosecha suficiente para alimentarse el resto del primer año de casados. Estos regalos recibían en algunas zonas el nombre de rebodo ${ }^{44}$ Como describe C: Cabal:

43 Aurelio de Llano, Del folklore..., opus cit. pp. 206-215 y 220; Constantino Cabal, Las tradiciones populares asturianas I..., opus cit., pp. 101-102.

${ }_{44}$ Adolfo García Martínez, «Los ritos de paso», en VVAA, Enciclopedia de la Asturias Popular, vol, 4. El mundo de las ideas, La voz de Asturias, Oviedo, 1994; Roberto González-Quevedo, Antropología social y cultural de Asturias. Introducción a la Cultura Asturiana, Madú, Granda-Siero, 2002, pág 73; Joaquín Vilar Ferrán, Topografía mé- 
«De bebida sidra y vinos y por remate café. De noche cena y baile. A veces, por razones especiales, la boda es silenciosa y recogida; pero entonces es costumbre que el novio pague "una fiesta" a los mozos del lugar. En esta fiesta hay música y bebida y baile. Hasta ayer, de los gastos del convite pagaba el novio la carne, y con mucha frecuencia la bebida». ${ }^{45}$

En el término municipal de Tineo, entrado ya el siglo XX, aún existía la costumbre de la frarada que consistía en que en la víspera de la boda la madrina envolviese a la novia en una sábana y la metiese en la cama y, a la luz del candil y con un jarro de sidra, la velaba el novio hasta la madrugada, estando aquella presente. Cuando nacían los hijos la comensalidad también hacía acto de presencia. Por ejemplo, en el concejo de Parres, una vez verificado el alumbramiento, se congregaba a todo el pueblo en casa de la parturienta y se convidaba a todos a beber y comer. ${ }^{46}$

Otra de las ocasiones en que se rompía la monotonía campesina estaba relacionada con la muerte. El velatorio (en Asturias velorios o mazaricones) y el funeral constituía un acto comunitario que, para algunos de los participantes, podía constituir una ocasión lúdica. El consumo de sidra también se constata en estos rituales funerarios. Era costumbre celebrar un banquete en la casa en que fallecía uno de sus miembros, siendo generalmente los vecinos los que aportaban la comida y la bebida. La casa donde tenía lugar el velatorio solía ofrecer castañas y sidra a quienes se quedaban a pasar la noche - solían hacer los hombres tertulia en el exterior de la casa - y, tras el sepelio, se acostumbraba a dar a los pobres pan y sidra además de limosna. Por otra parte, en algunas zonas, hasta finales del siglo XIX al menos, el banquete mortuorio tenía lugar en el atrio de la iglesia parroquial. En ocasiones se llegaron a cometer tales excesos que, ya en el siglo XVIII, el obispo Pisador los llegó a prohibir severamente; no

dica del concejo de Cabrales, Establecimiento Tipográfico de «El Liberal», Madrid, 1921, p. 229; Elviro Martínez, Costumbres asturianas, Everest, León, 1980, p. 119; María de la P. Viyao, Datos antropo-etnográficos de la parte oriental de Asturias, en Dos estudios entnográficos sobre el oriente de Asturias (1920-1921), Museo del Pueblo de Asturias, Gijón, 2007, pp. 104-105; Beatriz Rato Rionda, Vida cotidiana n'Asturies (1900-1950), vtp, Gijón, 2001, pp. 39-41.

${ }^{45}$ Constantino Cabal, Las tradiciones populares asturianas I..., opus cit., p. 283.

46 Joaco López y Carmen Lombardía (eds.), Costumbres de nacimiento y muerte. Encuesta del Ateneo de Madrid, 1901-1902, Museo del Pueblo de Asturias, Gijón, 1998, pp. 71 y 26. 
obstante, la presencia de la costumbre en estos actos la pone de manifiesto «Clarín» en su cuento Manín de Pepa José durante el último cuarto de la siguiente centuria. ${ }^{47}$

Fuera de estas ocasiones excepcionales, la sociabilidad más cotidiana tenía su momento crítico los domingos. Por la tarde se solía acudir a la taberna del pueblo a beber sidra o vino y a jugar a los bolos, a la llave o chapa, y a la brisca (tresillo de los pobres) o al tute, tornando al oscurecer a sus hogares. La sociabilidad asociada al consumo de sidra era un elemento de primer orden para el disfrute de los domingueros, y daba lugar a más de un conflicto en torno a su consumo. Por ejemplo, la Guardia Civil de Oviedo recibía en 1925 orden de impedir, «con toda energía», el establecimiento los domingos de puestos ambulantes de venta de sidra y otras bebidas, a cargo de personas sin garantía alguna, que no satisfacían la contribución de ambulantes. En las parroquias se encargarían del asunto los alcaldes de barrio. Esta medida se ponía en marcha debido a que dichos puestos significaban una competencia ilegal a los establecimientos que satisfacían las contribuciones y los impuestos, y una merma de la Hacienda. ${ }^{48}$

La sidra, por mencionar un último caso que podía acabar cobrando una dimensión festiva, sería también utilizada como agente electoral, y no fue infrecuente el que candidatos de diversas tendencias intentasen comprar, o aletargar y doblegar las voluntades, recurriendo a copiosas y obsequiosas donaciones del ambarino caldo. De este modo tan gráfico lo expresaba el diario gijonés El Noroeste a la altura de 1905: «Como ayer hubo sidra de balde para muchos electores, abundaron las pítimas, no escaseando tampoco las broncas y reyertas». En 1918 volverá a insistir el diario en la utilización de la bebida como medio apto para la búsqueda de votos, calificando las donaciones etílicas de «pasatiempos electorales». ${ }^{49}$

El mantenimiento del calendario festivo tradicional asturiano, pues, continuó representando a lo largo de este periodo un elemento clave en el

47 Julio Vaquero, «Los rituales colectivos ante la muerte en Asturias durante el siglo XIX, a través de los testamentos. Notas metodológicas», Estudios sobre historia de España (Homenaje a Tuñón de Lara), t. II, Madrid, 1981, pp. 487-500; Octavio Bellmunt y Fermín Canella, «De Vita et...», op. cit., p. 25; Leopoldo Alas, «Clarín», «Manín de Pepa José», Cuentos, Plaza y Janés, Barcelona, 1986, pp. 331-332.

48 Octavio Bellmunt y Fermín Canella, «De Vita et Móribus...», op. cit., p. 23. La Prensa, 25-VII-1925.

49 El Noroeste, 13-XI-1905 y 11-II-1918. 
sostenimiento del tejido comunitario del agro regional, pese a que muchos de sus ingredientes característicos se encontrasen en vías de disolución o de transformación y redefinición. Comer y beber seguirían suponiendo actividades fundamentales en este contexto, contribuyendo de modo decidido a reforzar una solidaridad campesina renuente a adoptar los nuevos marcos convivenciales que imponía la sociedad industrial contemporánea. La vigencia y sólido arraigo de estas realidades, en fin, da cuenta de la efectividad de las estrategias de resistencia de la cultura popular ante los envites de unos sectores hegemónicos que pretendían socavarla y ejercer un férreo control social sobre ella, sobre todo ante unas costumbres en las que los excesos en la comida, y de modo especial en las libaciones etílicas, conducían con frecuencia a una alta tasa de absentismo laboral.

Por otra parte, se constata una rápida evolución en los hábitos de consumo, y parece claro que en una coyuntura económica favorable se produce una coexistencia - cuando no una sustitución - de menús festivos que se habrían estandarizado apenas unas décadas antes, tal y como ocurriría con la fabada. De este modo, se observa como la novedad en el ingrediente base de plato principal en los días de fiesta no radica en una mejora cualitativa, sino más bien en tratarse de un producto de importación como sucede en el caso de los garbanzos o el arroz. Además, se constata un acceso cada vez más frecuente a la degustación de platos elaborados a partir de carne de vaca y pollo, lo que no mucho tiempo atrás quedaba recluido a la economía de las familias más pudientes. En el caso de los postres tradicionales su vigencia deriva sin duda alguna de su laborioso proceso de manufactura, lo que implica que sólo pudiesen disfrutarse en contadas ocasiones. Finalmente, se puede señalar que estas celebraciones experimentarían un acelerado proceso de mercantilización o bien, en no pocas ocasiones, servirían de pretexto para acometer actos propagandísticos de variado tenor. 